\title{
Energy Storage Techniques for Hydraulic Wind Power Systems
}

\author{
Masoud Vaezi, Afshin Izadian, Senior Member, IEEE \\ Energy Systems and Power Electronics Laboratory \\ Purdue School of Engineering and Technology, IUPUI \\ Indianapolis, IN, USA \\ aizadian@iupui.edu
}

\begin{abstract}
Hydraulic wind power transfer systems allow collecting of energy from multiple wind turbines into one generation unit. They bring the advantage of eliminating the gearbox as a heavy and costly component. The hydraulically connected wind turbines provide variety of energy storing capabilities to mitigate the intermittent nature of wind power. This paper presents an approach to make wind power become a more reliable source on both energy and capacity by using energy storage devices, and investigates methods for wind energy electrical energy storage. The survey elaborates on three different methods named "Battery-based Energy Storage", Pumped Storage Method, and "Compressed Air Energy Storage (CAES)".
\end{abstract}

Keywords-Renewable Energy; Energy Storage; Wind Power systems; Hydraulic Transfer System.

\section{INTRODUCTION}

There has been a significant improve in wind energy generation systems throughout recent years. However, high capital investments and low capacity factors are still the remaining issues [1,2]. Holding the stresses applied by the weight of the structure requires reliable foundations which considerably increases the implementation cost. The average lifetime of the conventional wind turbines is almost 20 years. However, their gearboxes should be replaced after the operation period of 5 to 7 years, and this replacement can be as costly as 10 percent of the entire turbine [3-6]. In the conventional wind farms, each wind turbine is comprised of a gear box, power electronics, and a generator all implemented in nacelle. Recently, new generation of wind turbines is introduced in which a hydraulic system is designed and utilized to provide several advantages over conventional systems [7-10]. Hydraulic wind power transfer systems require a light weight foundations as they get rid of bulky equipment in nacelle such as generator and gearbox. Fig. 1 illustrates the hydraulic wind power transfer system where a pump coupled with the wind turbine is used to generate highpressure hydraulic fluid to transfer the power. The pressurized fluid, generated by the hydraulic pumps, is directed to run the generators on the ground level [11]. In this system, the energy transfer can be controlled by distributing the flow between the hydraulic motors [12,13].

The new wind energy harvesting technique for hydraulic wind power systems should incorporate power generation equipment of individual towers in a central power generation unit. By introducing the new generation of wind turbines, instead of utilizing the bulky electro-mechanical components, a hydraulic pump is accommodated is the wind tower. The function of this hydraulic pump is to pressurize a fluid through a circuit which passes the hydraulic motor coupled with generator at ground level. This approach will provide several benefits over the conventional systems such as increased life span, better reliability, and less maintenance requirement which will reduce the operation cost in the wind turbine towers. Higher rate of energy transfer and size reduction of the power electronics are other advantages of hydraulic wind turbines [14-18].

The energy harvesting from intermittent sources, require energy storage units to smooth out the generation of power and frequency stability, which can easily deviate from $60 \mathrm{~Hz}$ as the wind speed changes. High-pressure hydraulic systems provide an excellent platform for incorporation of mechanical and electrical energy storage units.

This paper addresses the circuitry needed for energy storage of hydraulic wind power systems and studies different methods of energy harvesting. In general, high wind speeds result in generation of excess flow in the system. The energy of this flow is captured by an auxiliary generator and stored in a storage unit. The stored energy is released back to the system to run the main pump when the wind speed drops. In this case, the flow generated by the wind turbine is augmented by the auxiliary pump flow to maintain the angular velocity demands of the loaded primary generator.

\section{HYDRAULIC WIND ENERGY TRANSFER}

The hydraulic wind power transfer system is comprised of various parts such as hydraulic pumps and motors, proportional valves, check valves, and pressure relief valves. A prime mover (wind turbine blades) is utilized in this configuration to drive a fixed displacement pump. Also, to transmit the captured power, one or more fixed displacement

This is the author's manuscript of the article published in final edited form as: Vaezi, M., \& Izadian, A. (2014). Energy storage techniques for hydraulic wind power systems. In 2014 International Conference on Renewable Energy Research and Application (ICRERA) (pp. 897-901). http://doi.org/10.1109/ICRERA.2014.7016514 
hydraulic motors are employed. At the upstream, the implemented pump transforms the mechanical power from the blades' shaft to the pressurized fluid and then the captured energy is transferred to the hydraulic motors through hydraulic hoses and pipes $[8,19]$.

Wind power is harvested using a high-torque low speed turbine. Intermittent wind speed introduces hydraulic flow fluctuations from the prime mover that eventually changes the electric power flow in the system. Steady electric power generation requires steady flow of pressurized hydraulic medium to the main hydraulic motor. Proportional valves are used to regulate and control the hydraulic flow to manage the electric power generation

Fig. 1 depicts a schematic diagram of hydraulic wind power transfer systems. As it can be seen in the figure, the blade's shaft is connected to a hydraulic pump. The rotation of this shaft makes the pump to pressurize a flow down to the circuit where there are several safety hydraulic components in the way such as pressure relief valves. At the downstream, high pressure flow passes through hydraulic motors which are coupled with electric generators to generate electrical power. For this purpose, hydraulic hoses and steel pipes are utilized to connect the pump to the power generation unit. In addition, the hydraulic pump employed in the circuit should have a large displacement so that it can transfer the power to the power generation unit. This is as a result of produced large amount of torque compared to low angular velocity [7].

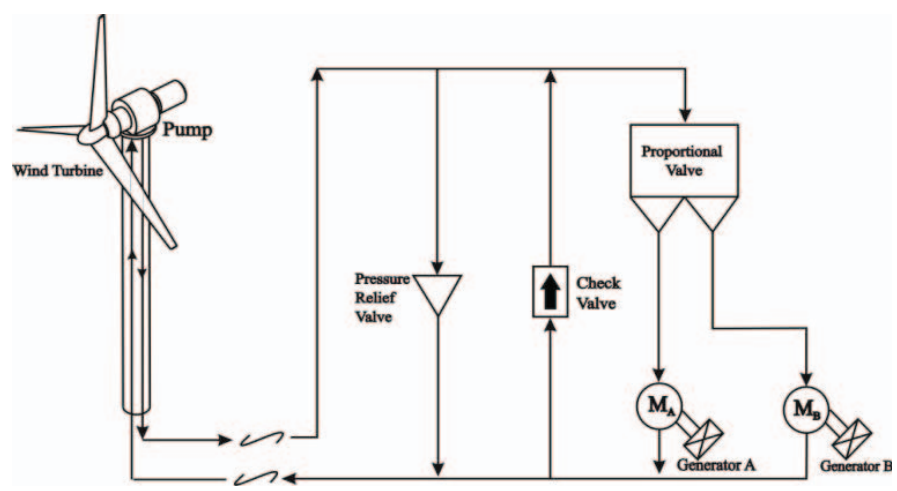

Figure 1. Schematic of hydraulic wind power transfer systems.

In this configuration pressure relief valves are considered to protect the system components from the destructive impact of localized high-pressure fluids. In addition, check valves force the hydraulic flow to be unidirectional. Finally, the proportional valve distributes a controlled amount of flow to each hydraulic motor to be converted to the electrical power by the generators [20-22].

A prototype is implemented as a test bed for hydraulic wind power transfer technology in the Energy Systems and Power Electronics Laboratory, IUPUI. Fig. 2 demonstrates an overlay of the experimental setup and hydraulic circuitry. An electric motor was used to drive the hydraulic pump through the pulley and belt to reduce the pump shaft speed. The system operating conditions, such as angular velocity and pressures, are precisely measured by fast prototyping in dSPACE 1104 hardware. The outcome of this study on energy storage techniques of hydraulic wind power systems is going to be utilized for further implementation on this experimental setup.

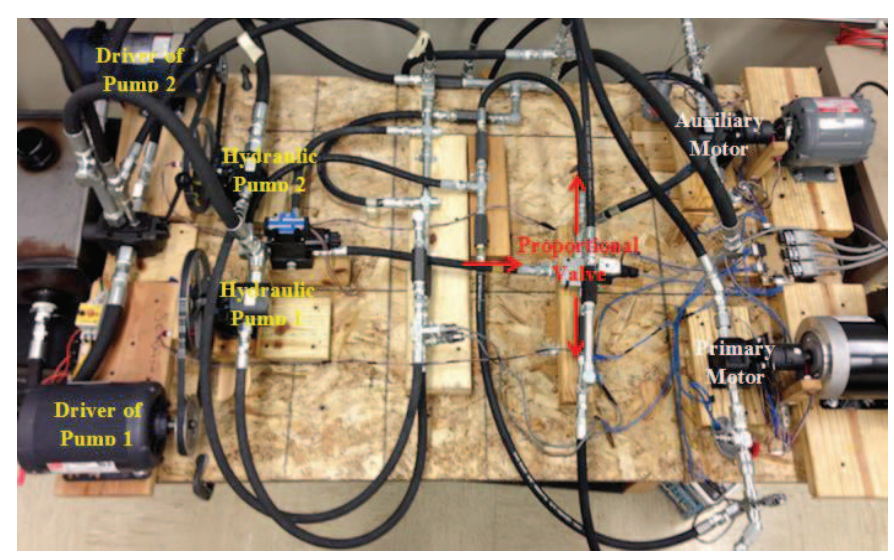

Figure 2. Experimental setup of the hydraulic wind power transfer system. Energy Systems and Power Electronics Laboratory.

\section{MOdEl DEVElopMENT OF HYdRAULIC WIND POWER SYSTEMS}

Understanding the dynamics of the system through the mathematical modeling considerably helps to choose the best energy storage technique and related control system. To derive the state space representation of the hydraulic wind power system, the integrated configuration of the hydraulic components must be considered. Nonlinear governing equations of utilized hydraulic components are provided in [4] and [11]. Using these equations, a nonlinear model of hydraulic wind power transfer systems are proposed in state space representation and experimentally verified. State space representation offers several benefits such as the ease of implementation, stability analysis, and model understanding [23-27].

In general, the nonlinear state space model of a system can be represented as

$$
\begin{aligned}
& \dot{x}=f(x)+g(x) U \\
& y=h(x),
\end{aligned}
$$

where $x$ is the state vector, $y$ is the output vector, $U$ is the input vector, $f(x)$ is an input independent function vector of the states, $g(x)$ is the input dependent function matrix of the state variables, and $h(x)$ is the output function. The state space model is achieved in [11] with states and inputs as follows:

$$
x=\left[\begin{array}{lllll}
P_{p} & P_{m A} & P_{m B} & \omega_{m A} & \omega_{m B}
\end{array}\right]^{T}, \quad U=\left[\begin{array}{c}
h_{i} \\
\omega_{p}
\end{array}\right],
$$


where the inputs to the hydraulic system are $\omega_{p}$, the angular velocity of the hydraulic pump (wind speed), and $h_{i}$, the position of the proportional valve. The state variables are the pressure of the pump $\left(P_{p}\right)$, pressure of the Motor A $\left(P_{m A}\right)$, pressure of the motor $\mathrm{B}\left(P_{m B}\right)$, the primary motor angular velocity $\left(\omega_{m A}\right)$, and the auxiliary motor angular velocity $\left(\omega_{m B}\right)$.

\section{ENERGy StORAgE TECHNIQUES For Wind POWER SYSTEMS}

There are some approaches to compensate for stochastic nature of wind. For instance, adding a storage system to the power generation unit can considerably reduce the fluctuation of the system. However, this will require a capital investment for the storage system. Therefore, there is crucial need for studying reasonable storage technologies for desired applications and reducing the output variation in the system.

In recent decades, energy storage systems have drawn a great attention because of the high costs of energy carriers. Considering fluctuating nature of wind, storing wind energy in the related plants is of high importance and can highly improve the efficiency of the system. Throughout normal operation in a day, the generated electricity can be stored in different ways such as compressed air, when a large amount of implemented systems is out of service and power generation cost is low and also when network cannot feed the grid. There are some methods to store energy in systems which include mechanical and electrical specific for wind power systems. In the literature, some approaches are proposed to store the generated energy such as compressed air energy storage (CAES), gravitational energy storage or pumped hydropower storage (PHPS), and flywheels. The flywheel technology can be used for intermediate storage while the CAES is more suitable for largescale utility energy storage. Finally, one the well-known approaches for storage of electrical energy is to employ batteries.

In the next subsections, the comparison of "Compressed Air Energy Storage (CAES)", "Battery-based Energy Storage", and "Pumping Storage Hydroelectricity (PSH)" will be provided.

\section{A. CAES Method}

The CAES method captures excess power prior to electricity generation so that electrical components can be downsized for demand instead of supply. In this method, as usual, energy is stored in a high pressure dual chamber liquidcompressed air storage vessel. It takes advantage of the power density of hydraulics and the energy density of pneumatics in the "open accumulator" architecture [28,29]. A liquid piston air compressor/expander is utilized to achieve near-isothermal compression/expansion for efficient operation. A dynamic system model as well as control laws for optimizing the turbine power, delivering required electrical power and maintaining system pressure are developed in [30,31].

A novel Compressed Air Energy Storage (CAES) concept for wind turbines was proposed in [32]. In this proposed CAES system, excess energy from the wind turbine is stored locally, prior to electricity generation, as compressed air in a storage pressure vessel. This allows electrical components to be downsized. The compressor/expander used to store and extract energy operates nearly isothermal so that it is efficient. A variable hydraulic drive, instead of a mechanical gearbox, is used for power transmission. This improves the reliability of the transmission system and allows the generator and the storage system to be housed down tower, thus reducing construction and repair costs. In addition, a cost effective fixed speed inductor generator can be used instead of the combination of a permanent magnet synchronous motor and power electronics for frequency conversion.

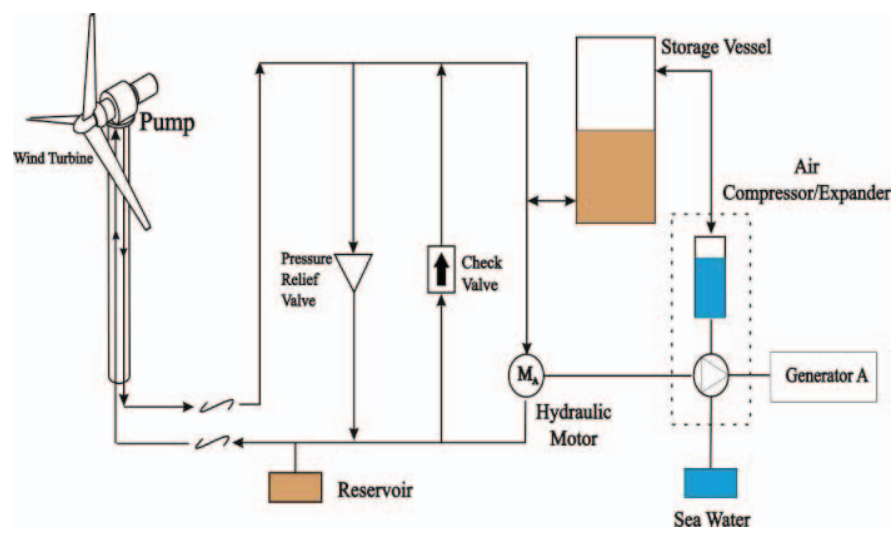

Figure 3. Compressed air energy storage system coupled to a hydralic wind turbine

The CAES uses the "open accumulator" architecture as shown in Fig. 3. A variable displacement hydraulic pump is attached to the wind turbine rotor in the nacelle which converts wind power to hydraulic power. At the sea level there is a tandem connection of a variable displacement hydraulic pump/motor, a near-isothermal liquid piston air compressor/expander and a fixed speed induction generator. They are driven by the hydraulic pump, and exchange powers hydraulically or pneumatically with the high pressure storage vessel. The storage vessel contains both liquid and compressed air at the same pressure. Energy can be stored or extracted by pumping or releasing i) pressurized liquid similar to a conventional hydraulic accumulator; or ii) compressed air similar to a conventional air receiver.

Two major challenges are: 1) compressor/expanders are generally not very efficient or powerful; 2) the pressure in the storage vessel reduces as compressed air in the storage vessel depletes, making it difficult for the air compressor/expander to maintain either its efficiency or power at all energy levels. The first challenge is overcome by developing a liquid piston air compressor/expander with enhanced heat transfer and reduced leakage. The latter is overcome by deploying an "open accumulator" configuration [33] with a dual chamber storage vessel for both liquid and compressed air, such that energy can be stored/retrieved hydraulically and pneumatically. Therefore, storage vessel pressure can be maintained constant regardless of energy content, and the compressor/expander can be downsized for steady power instead of peak power [31]. 


\section{B. Battery-based Method}

In The Battery-based Energy Storage method, stored energy is released to the plant when the wind speed dropped below a certain threshold and storage happens during charge and discharge of specific battery which the efficiency of the system can be raised by controlling the system [34].

\section{1) High Wind Speed Operation}

The wind speed fluctuates over time. Therefore, utilization of fixed displacement pumps result in flow variation in the system. If the wind speed is higher than the reference that generates $60 \mathrm{~Hz}$ voltage in the output, the condition is called high wind. If the excess flow of power and its energy is not captured, the generator's voltage frequency will deviate from $60 \mathrm{~Hz}$. The proportional valve is regulated such that the required flow is delivered to the primary hydraulic motor, and the excess energy is captured by the auxiliary hydraulic motor. The auxiliary hydraulic motor is coupled with an electric motor/generator. At high wind, the auxiliary hydraulic motor runs the electric generator. The electric generator converts the mechanical energy of the rotating shaft into electric energy and stores it in batteries. Fig. 4 shows the schematic of the system operation at high wind speed.

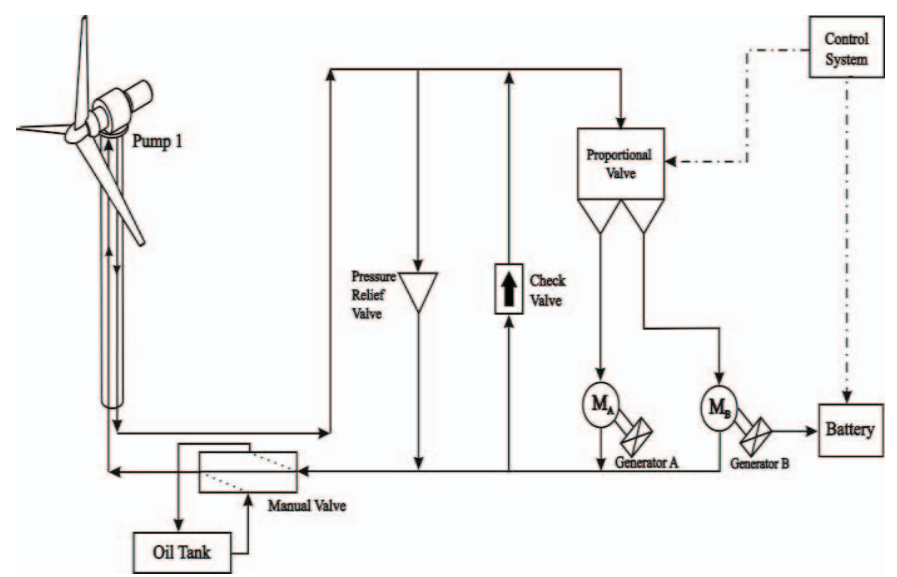

Figure 4. The schematic of the system operation at high wind speed

\section{2) Low Wind Speed Operation}

If the wind speed drops below a threshold speed, the condition is considered low wind. In this condition, the flow generated by hydraulic pump is not sufficient enough to maintain the reference angular velocity at the primary motor. In order to compensate for the flow deficiency, the energy stored in the storage should be released back to the system. The storage in any form can run the auxiliary hydraulic pump to generate an augmented pressurized fluid in the system. Fig. 5 illustrates the schematic of the system operation at low wind speed [34].

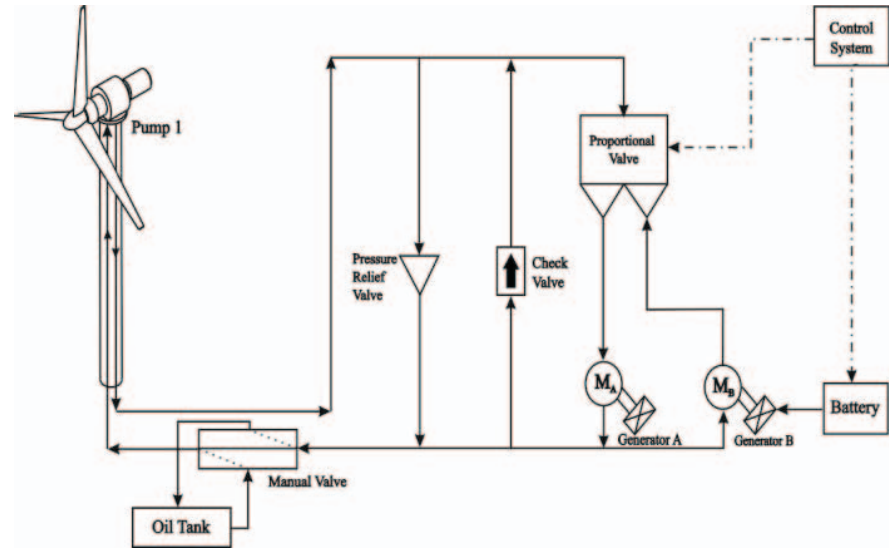

Figure 5. The schematic of the system operation at low wind speed

\section{Pumping Storage Method}

One of the approaches to store the electricity is called pumped storage which stores energy in the form of water lifted from a lower reservoir into a higher one. In the low-cost offpeak operation of the plant, the amount of electrical power which is excess, can be utilized to run a pump to pressurize water. For the second case scenario, when there is a high electrical demand, the stored water can be released. Similarly, in a hydraulic wind power transfer system, at time of low electrical demand, excess power produced by the system is used to pump water into a higher reservoir and then, when there is a higher demand, the water is released back in the lower reservoir through a turbine [35].

There are two possibilities:

1) Two waterways: one for pumping, one for the turbine;

2) One unique water way: reversible machinery can be used for both pumping and generating; it is designed as a motor and pump in one direction and as a turbine and generator in the opposite rotation.

Under favorable geological conditions, the station is located underground. Various pumped storage plants exist worldwide with power varying from $1 \mathrm{MW}$ to $2700 \mathrm{MW}$. Pumped hydro is available at almost any scale with discharge times ranging from several hours to a few days. The advantages of such systems are [36]:

- More than 100 years of experience,

- High efficiency.

- Multipurpose facilities;

- Environmental friendly;

- $\mathrm{CO}_{2}$ avoiding;

- Highest availability compared to other technologies;

- Quick response to load variation (few seconds) and reserve capacity [37].

\section{CONCLUSION}

This paper presented three energy storage techniques to capture the excess energy of hydraulic wind transmission 
system. CAES method has a great number of advantages. For instance, CAES systems are more suitable for very large scales. These systems can be utilized with the entire power plants as well. On the other hand, the high cost of batteries is one of the main drawbacks of Battery storage method. Also, pumped storage method has some considerable advantages. Improved quality for generated electricity as well as reducing the peak power of the system are some of the benefits of hydro-pumped storage technology. This system flattens out the load variation on the power grid, and permits thermal power stations, that provide base-load electricity, to continue operating at peak efficiency while reducing the need for peaking power plants that use costly and polluting fuels. However, they might not be suitable for large scale systems.

\section{ACKNOWLEDGMENT}

This work was published from the Inaugural Grant Award through the Vibration Institute.

\section{REFERENCES}

[1] A. Izadian, N. Girrens, "The U.S. and E.U. Renewable Energy Policies," IEEE Industrial Electronics Magazine, to appear 2013.

[2] M. Vaezi, M. Deldar, and A. Izadian, "Hydraulic Wind Power Plants: Nonlinear Model of Low Wind Speed Operation," Control Systems Technology, IEEE Transactions on, 2014.

[3] A. Ragheb, and M. Ragheb, "Wind Turbine Gearbox Technologies," Proceedings of the 1st International Nuclear and Renewable Energy Conference (INREC10), Amman, Jordan, March 2010.

[4] S. Hamzehlouia, A. Izadian, A.,"Nonlinear State Space Modeling of Gearless Wind Power Systems," IECON 2012, pp. 1098-1103.

[5] M. Vaezi and A. Izadian, "Piecewise Affine System Identification of a Hydraulic Wind Power Transfer System," Control Systems Technology, IEEE Transactions on, Accepted, 2014.

[6] M. Vaezi and A. Izadian, "Multiple-Model Adaptive Estimation of a Hydraulic Wind Power System," in Industrial Electronics Society, IECON 2013-39th Annual Conference of the IEEE, Vienna, Austria, 2013, pp. 2111-2116.

[7] S. Eriksson, H. Bernhoff, and M. Leijon, "Evaluation of Different Turbine Concepts for Wind Power," Renewable and Sustainable Energy Reviews, vol. 12, issue 5, pp. 1419-1434, June 2008.

[8] A. Izadian, "Central Wind Turbine Power Generation," US Patent Application, US 20130127166, May 23, 2013.

[9] http://www.chapdrive.com/technology/5-mw-project

[10] http://www.mhi.co.jp/en/news/story/1111291475.html

[11] S. Hamzehlouia, and A. Izadian, "Modeling of Hydraulic Wind Power Tranfers," Power and Energy Conference Illinois, PECI 2012.

[12] S. Hamzehlouia, A. Izadian, A. Pusha and S. Anwar, "Controls of Hydraulic Wind Power Transfer," IECON 2011.

[13] M. Vaezi, A. Izadian, and M. Deldar, "Adaptive Control of a Hydraulic Wind Power System Using Multiple Models," in Industrial Electronics Society, IECON 2014-40th Annual Conference of the IEEE, Dallas, USA, 2014.

[14] L. Shi, Z. Xu, C. Wang, L. Yao, and Y. Ni, "Impact of Intermittent Wind Generation on Power System Small Signal Stability", 2011 under CC BY-NC-SA 3.0 license

[15] S. Gao, and N. Zhang "A Review of Different Methodologies for Solving the Problem of Wind Power's Fluctuation," International Conference on Sustainable Power Generation and Supply (SUPERGEN '09), pp. 1-52009.

[16] P. Sorensen, N. A. Cutululis, A. V. Rodriguez, L. E. Jensen, J. Hjerrild, M. H. Donovan, and H. Madsen, "Power Fluctuations from Large Wind Farms," IEEE Transaction on Power Systems, vol. 22, no. 3, August 2007.

[17] K. Ogata, Modern Control Engineering, 5th Edition, Prentice Hall, 2010.
[18] M. Vaezi, A. Izadian, and M. Deldar, "A Model Linearization Technique for Hydraulic Wind Power Systems," in Power and Energy Conference at Illinois (PECI), IEEE, Urbana, USA, 2014, pp. 1-5.

[19] K. Wu, et al., "Modeling and identification of a hydrostatic transmission hardware-in-the-loop simulator," International Journal of Vehicle Design, vol. 34, pp. 52-64, 2004.

[20] A. Edalatnoor, A. Izadian, and M. Vaezi, "Indirect adaptive control of droplet dispensing in digital microfluidic systems," in Industrial Electronics Society, IECON 2013-39th Annual Conference of the IEEE, Vienna, Austria, 2013, pp. 3580-3585.

[21] H. E. S. Jazeh, M. Vaezi, F. C. Samavati, and S. A. A. Moosavian, "The robustness analysis of two motion control algorithms for Stäubli TX40 robot in object manipulation task," in Mechatronics and Automation (ICMA), 2011 International Conference on, Chengdu, China, 2011, pp. $2165-2170$.

[22] M. Vaezi, H. Jazeh, F. Samavati, and S. A. A. Moosavian, "Singularity analysis of 6DOF Stäublic TX40 robot," in Mechatronics and Automation (ICMA), 2011 International Conference on, Chengdu, China, 2011, pp. 446-451.

[23] H. E. Merritt, "Hydraulic control systems", New York, John Wiley Inc., 1967

[24] E. C. Fitch, I. T. Hong, "Hydraulic component design and selection", Oklahama, BarDyne Inc, 1998

[25] Blackburn, J.F., Reethof, G., and Shearer, J.L., Fluid Power Control, The M.I.T. Press, Cambridge, MA, 1960

[26] A. V. Akkaya, "Effect of Bulk Modulus on Performance of a Hydrostatic Transmission Control System" Sadhana, vol. 31, Part. 5, October 2006, pp. 543-556.

[27] M. Deldar, A. Izadian, M. Vaezi, and S. Anwar, "Modeling of a Hydraulic Wind Power Transfer Utilizing a Proportional Valve," Industry Applications, IEEE Transactions on, Accepted, 2014.

[28] M. Vahedipour Dahraie, H. R. Najafi R. Nasirzadeh Azizkandi M.R.Nezamdoust, "Study on compressed air energy storage coupled with awind farm", Renewable Energy and Distributed Generation(ICREDG), 2012 Second Iranian Conference, March 2012, pp. $147-152$.

[29] Mautoux R. D., "Wind Integrated Compressed Air Energy Storage in Colorado", Master of science thesis, Department of Electrical Engineering, University of Colorado, 2007.

[30] F. Cheraghpour, M. Vaezi, H. Jazeh, and S. Moosavian, "Dynamic modeling and kinematic simulation of Stäubli@ TX40 robot using MATLAB/ADAMS co-simulation," in Mechatronics (ICM), 2011 IEEE International Conference on, Istanbul, Turkey, 2011, pp. 386-391.

[31] M. Saadat, and P. Y. Li, "Modeling and Control of aNovel Compressed Air Energy Storage System for OffshoreWind Turbine,” 2012 American Control Conference, Montreal,Canada, June, 2012.

[32] P. Y. Li, E. Loth, T. W. Simon, J. D. Van de Ven, and Stephen E.Crane, "Compressed Air Energy Storage for Offshore WindTurbines," 2011 International Fluid Power Exhibition (IFPE), LasVegas, NV, March, 2011.

[33] Li, P., Van de Ven, J., and Sancken, C., "Open Accumulator Conceptfor Compact Fluid Power Energy Storage," Proceedings of the ASMEInt. Mechanical Engineering Congress, Seattle, WA, 2007, pp 42580.

[34] Sina Hamzehlouia, Afshin Izadian, and Sohel Anwar, "An Energy Storage Technique for Gearless Wind Power Systems", IEEE International Conference on Electro/Information Technology (EIT), 2013.

[35] Muyeen,S.M., "Wind Energy Conversion Systems", Springer Publication, ISBN 978-1-4471-2201-2.

[36] A. Estanqueiro, et al., "Energy storage for wind integration: Hydropower and other contributions," IEEE Power and Energy Society General Meeting, San Diego, CA, July 2012.

[37] C. Cristofari, Gilles N otton, Motaz Ezzat, and et all, "Pumped Hydroelectric Storage Coupling Wind-Solar Resources: A Solution for Increase Ren on Islands Electrical Grid", International Conference on Energy and Sustainable Development: Issues and Strategies (ESD 2010). 